\title{
Ultrahigh vacuum high-pressure reaction system for 2-infrared 1-visible sum frequency generation studies
}

Cite as: Review of Scientific Instruments 72, 1806 (2001); https://doi.org/10.1063/1.1329902

Submitted: 03 July 2000 . Accepted: 10 October 2000 . Published Online: 27 February 2001

K. Y. Kung, P. Chen, F. Wei, G. Rupprechter, Y. R. Shen, and G. A. Somorjai

ARTICLES YOU MAY BE INTERESTED IN

Atmospheric pressure reaction cell for operando sum frequency generation spectroscopy of ultrahigh vacuum grown model catalysts

Review of Scientific Instruments 89, 045104 (2018); https://doi.org/10.1063/1.5021641

Sample mounting and transfer mechanism for in situ IR-visible sum frequency generation vibrational spectroscopy in high-pressure ultrahigh vacuum system

Review of Scientific Instruments 74, 4554 (2003); https://doi.org/10.1063/1.1606529

Ultrahigh vacuum compatible all-glass high pressure reaction cell for accurate and reproducible measurement of small reaction rates

Review of Scientific Instruments 71, 1495 (2000); https://doi.org/10.1063/1.1150486

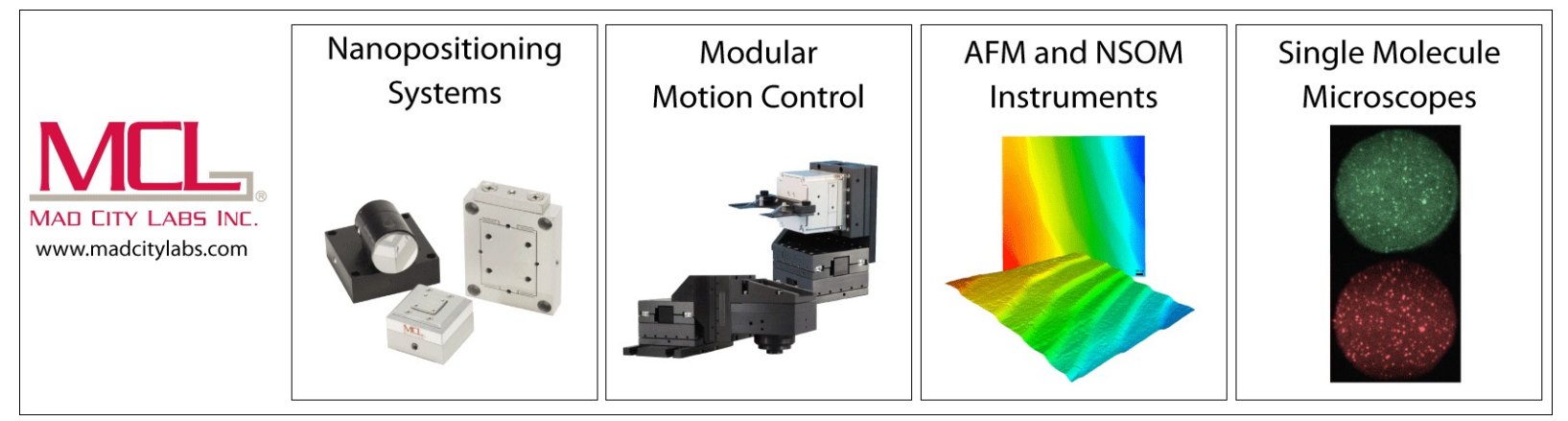

Review of Scientific Instruments 72, 1806 (2001); https://doi.org/10.1063/1.1329902

72, 1806

(c) 2001 American Institute of Physics. 


\title{
Ultrahigh vacuum high-pressure reaction system for 2-infrared 1-visible sum frequency generation studies
}

\author{
K. Y. Kung, P. Chen, F. Wei, and G. Rupprechter ${ }^{a)}$ \\ Department of Chemistry, University of California, Berkeley, California 94720 \\ and Materials Science Division, Lawrence Berkeley National Laboratory, Berkeley, California 94720 \\ Y. R. Shen \\ Department of Physics, University of California, Berkeley, California 94720 \\ and Materials Science Division, Lawrence Berkeley National Laboratory, Berkeley, California 94720 \\ G. A. Somorjaib) \\ Department of Chemistry, University of California, Berkeley, California 94720 \\ and Materials Science Division, Lawrence Berkeley National Laboratory, Berkeley, California 94720
}

(Received 3 July 2000; accepted for publication 10 October 2000)

\begin{abstract}
We designed an ultrahigh vacuum high-pressure (UHVHP) reaction system for in situ sum frequency generation studies. This system allows for pressure $\left(10^{-9}\right.$ Torr $\left.-1 \mathrm{~atm}\right)$, and temperature $(150-1100 \mathrm{~K})$ dependent investigation of adsorbates on single crystals or polycrystalline foils and of catalytic reactions. By combining two optical parametric systems, we are able to simultaneously detect $\mathrm{CO}$ and ethylene on $\mathrm{Pt}(111)$ surface. A gas chromatograph is used to monitor the kinetics of ethylene hydrogenation on $\mathrm{Pt}(111)$. (C) 2001 American Institute of Physics.
\end{abstract}

[DOI: $10.1063 / 1.1329902]$

\section{INTRODUCTION}

Sum frequency generation (SFG) vibrational spectroscopy has been proven to be a unique surface probe. ${ }^{1}$ It allows the studies of the structure and concentration of adsorbed species and their behavior during reactions under high ambient pressures. ${ }^{2-6}$ Such in situ studies provide the vital information about the surface intermediates in the catalytic reactions that is not accessible by other measurements. There is a need to monitor coadsorbed species simultaneously and in different chemical environments. We describe here the laser and ultrahigh vacuum (UHV)/high-pressure (HP) systems that permit such investigation.

In our first generation design, ${ }^{2,3}$ a conventional UHV chamber was used for high-pressure studies. This design suffered from several drawbacks: first the reaction volume was too large to study low turnover catalytic reactions. Second, gas phase absorption of the infrared beam became significant at high pressure due to long optical path. Third, it took hours for the system to pump down to base pressure after highpressure experiments, which prohibited the postreaction studies by the conventional surface science techniques. To overcome these problems, we designed a compact, detachable high-pressure cell as our second generation apparatus for in situ SFG studies.

In the following sections, we first describe the UHVHP cell, its designs and novel features. Then the laser system is discussed that provides one visible and two tunable infrared beams for simultaneous SFG spectroscopic measurements in two spectral regions. The result of experimental studies are shown as examples to illustrate how these systems work.

\footnotetext{
${ }^{a}$ Current address: Fritz-Haber-Institut der Max-Planck-Gesellschaft, Chemical Physics Department, Faradayweg 4-6, D-14195 Berlin, Germany.

${ }^{b)}$ Electronic mail: somorjai@ socrates.berkeley.edu
}

\section{UHVHP TRANSFER SYSTEM}

Our UHVHP system was composed of a UHV chamber for sample preparation and characterization and a detachable high-pressure reaction cell. The sample could be transferred between the two compartments. ${ }^{7-12}$ Our reaction cell has the following special features: (1) it is small so that low turnover reactions could be monitored by a gas chromatograph. (2) It has a large window to accommodate SFG measurements with three noncollinear input laser beams. (3) It could be detached from the UHV chamber and moved to other systems for complementary spectroscopic measurements. With separate pumping and gas handling systems, the reaction cell could be pumped down to $5 \times 10^{-9}$ Torr in $5 \mathrm{~min}$ after atmospheric pressure experiments.

Below we describe in detail the individual components of the system.

\section{A. UHV chamber}

The UHV chamber was a commercial Varian 601 stainless steel chamber pumped by a $250 \mathrm{l} / \mathrm{s}$ ion pump, a titanium sublimation pump, and a $360 \mathrm{l} / \mathrm{s}$ Lybold turbo molecular pump. It was equipped with a cylinder mirror analyzer for Auger electron spectroscopy and a quadrapole mass spectrometer for mass spectroscopy. An ion gun was used for sample cleaning by argon sputtering. Gases could be introduced into the chamber through leak valves. The sample mount was controlled by a sample manipulator with adjustable motion in $x, y, z, \theta$, and tilt, and the UHV docking mount was attached to the manipulator shaft. Copper braids were connected to the UHV docking mount for resistive heating and cooling. 


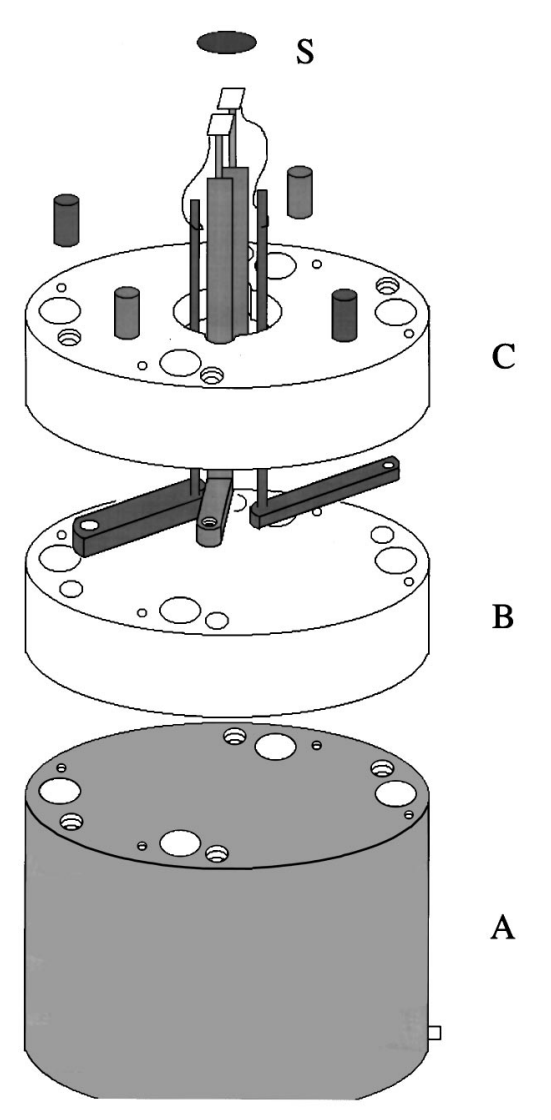

FIG. 1. (a) Stainless steel backing which is a 0.5 in. thick, 1 in. diameter cylinder with a square hole cut in the back to attach to a standard $0.5 \mathrm{in}$. ratchet head. A $3 / 16$ in. diameter locking pin that is $1 / 8 \mathrm{in}$. long is welded to the side. (b) A 0.25 in. thick ceramic piece used to separate the power pins for resistive heating from the backing. (c) Another 0.25 in. thick ceramic piece fits over the pins with the long side of the pins sticking through the hole in the middle and short side sticking through the outer through holes. S is the sample.

\section{B. Sample mount}

The sample mount was composed of a stainless steel backing, two ceramic pieces, two L-shaped copper posts, two stainless steel posts, and two L-shaped $K$-type thermocouples assembled as shown in Fig. 1. The stainless steel backing was a 0.5 in. thick, $1 \mathrm{in}$. diameter cylinder with a square hole cut in the back to attach to a standard 0.5 in. ratchet head. The first ceramic piece was used to separate the power pins for resistive heating from the backing, in essence acting as an electrobreak. The ceramic piece was a 0.25 in. thick Macor disk which was held to the steel backing. Four L-shaped pins were placed on top of the Macor electrobreak. Two of the L-shaped pins were made of Glid-Cop (copper doped with $1.5 \%$ alumna for hardness at high temperatures) for electrical and thermal conduction and the other two pins were for type $K$ thermocouple connections. Four L-shaped pins were set $90^{\circ}$ to each other with the Glid-Cop pins set $180^{\circ}$ apart. The long side of the L-shaped pins were placed near the center with the short end near the edge of the Macor disk. The top ceramic piece was machined to inset the thin rectangle bridge so that the top and bottom ceramic pieces could sit flush with each other. The top ceramic piece was held to the stainless backing by four screws. The two stainless pins were the platform to which the sample was attached. A Pt(111)

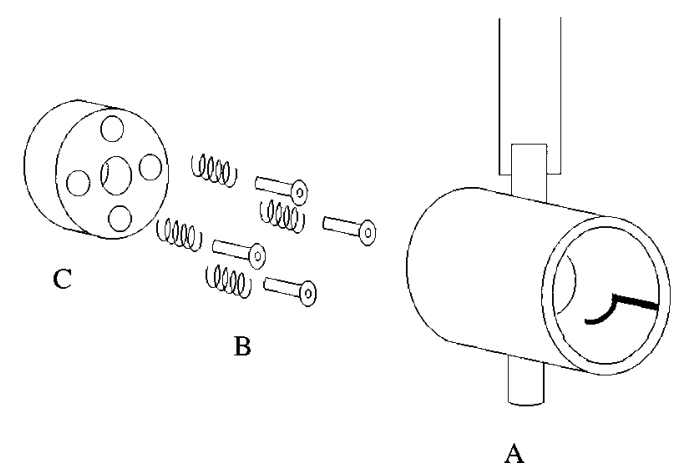

FIG. 2. The UHV docking mount: (a) The main housing, which is a stainless steel cylinder with hole cut in the center to fit the sample mount. A 3/16 in. groove $1 \mathrm{in.} \mathrm{long} \mathrm{is} \mathrm{cut} \mathrm{on} \mathrm{the} \mathrm{inside} \mathrm{edge} \mathrm{along} \mathrm{the} \mathrm{long} \mathrm{axis} \mathrm{of} \mathrm{the}$ cylinder. The purpose of the grooves is to guide the sample mount through the locking pin. (b) Four spring-loaded pins, which connect to the sample mount to transfer power and make thermocouple connections. (c) The ceramic disk capping the end of the stainless steel cylinder. The disk has a center hole to allow only the sample to pass through.

single crystal was spot welded on the back to the stainless posts. $K$-type thermocouple wires were spot welded to the back of the crystal for the temperature measurement.

\section{UHV docking mount and transfer arm}

The UHV docking mount (Fig. 2) was located at the end of the sample manipulator and provided electrical and thermocouple connections to the sample mount. It was composed of three main components: (1) a stainless steel cylinder with a hole cut at the center to fit the sample mount. A long groove was cut on the inside wall in order to be able to lock and hold the sample mount in place. (2) A ceramic Macor disk capped the end of the cylinder. It had a center hole to allow only the sample to pass through. (3) Four spring loaded pins connected to the sample mount to transfer power and make thermocouple connections. The sample mount could be transferred between the UHV docking mount and the high-pressure reaction cell by a magnetically coupled transfer arm.

\section{High-pressure reaction cell}

The high-pressure cell was a $600 \mathrm{ml}$ stainless steel cell electroplated with gold to reduce reactivity (Fig. 3). The cell was connected to the UHV chamber through a gate valve. Two 2 in. $\mathrm{CaF}_{2}$ windows on the cell allowed input and output of both infrared and visible beams. The sample transfer arm was connected to the docking mount in the cell which was similar to the UHV docking mount. The transferred sample was made to situate close to the windows so that IR absorption in high-pressure gas would be minimized. One gate valve was sufficient to seal the reaction cell from the UHV chamber. However, if the cell were to detach from the UHV chamber then two gate valves would be necessary.

Three valves were attached to the cell for gas input, recirculation, and pumping. A gas manifold system was used to introduce high-pressure gases into the cell and for evacuation. A gas chromatograph was connected to the recircula- 


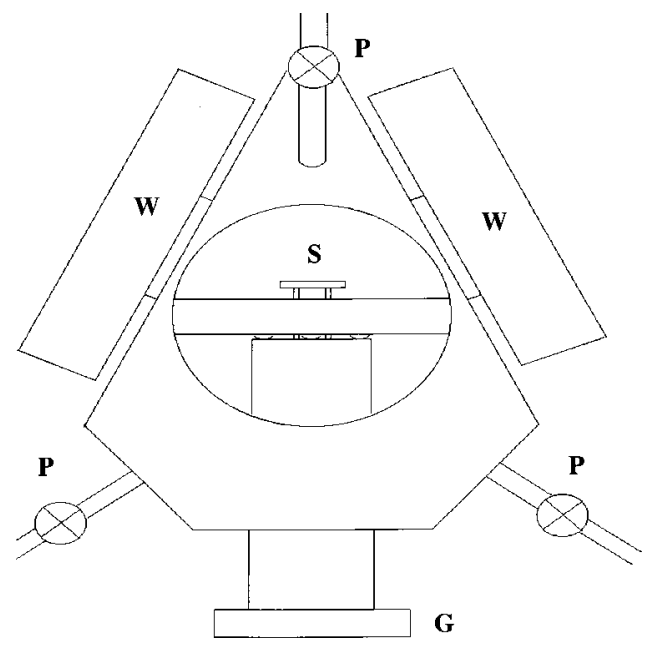

FIG. 3. The high pressure cell. It is electroplated with gold to reduce the reactivity. $\mathrm{S}$ : sample, $\mathrm{W}: \mathrm{CaF}_{2}$ window, $\mathrm{G}$ : gate valve, $\mathrm{P}$ : popit valve.

tion loop for gas analysis. A turbomolecular pump was employed to evacuate the cell to UHV pressures prior to its connection to the UHV chamber.

\section{LASER AND DETECTION SYSTEM}

The laser system was similar to the previous design. ${ }^{13}$ In order to perform 2-IR 1-Visible SFG, two separately tunable IR sources plus a visible $(532 \mathrm{~nm})$ beam were produced using a mode-locked picosecond pulsed YAG laser system. Infrared in the 5-8 $\mu \mathrm{m}$ range was generated by a combination of optical parametric generation (OPG) and optical parametric amplification (OPA) in two BBO crystals and then different frequency generation in a $\mathrm{AgGaS}_{2}$ crystal. Infrared in the $2-4 \mu \mathrm{m}$ range was generated by OPG/OPA in two $\mathrm{LiNbO}_{3}$ crystals. The $532 \mathrm{~nm}$ beam was generated by frequency doubling the YAG fundamental in a LBO crystal. Six rotational stepper motors (Newport) were used to tune the nonlinear crystals and grating. A Labview program (National Instruments) was designed to control all the stepper motors as well as to collect the SFG data and the reference IR intensity. For SFG measurement, the green and the two infrared beams were all $p$ polarized and their pulse energies at the surface were $250 \mu \mathrm{J}$ for the green, $100 \mu \mathrm{J}$ for the 2-4 $\mu \mathrm{m}$ range, and $80 \mu \mathrm{J}$ for the 5-8 $\mu \mathrm{m}$ range. And their incident angles on the samples were $55^{\circ}, 50^{\circ}, 60^{\circ}$, respectively. The infrared beams reflected from the entrance window and the sample were used to normalize the SFG intensity. Since two SFG output beams were created in the experiment, two separate detection systems were needed. Each detection system consisted of a $532 \mathrm{~nm}$ notch filter, an interference filter, a polarizer, a monochromator, and a photomultiplier tube. Wavelength calibration for the IR laser beams was done using polystyrene for the $\mathrm{C}-\mathrm{H}$ stretch region and gas phase $\mathrm{CO}$ and $\mathrm{CO}_{2}$ for the $\mathrm{CO}$ stretch region.

\section{EXPERIMENTAL RESULTS}

To demonstrate the utility of the optical system, we report here simultaneous measurements of sum frequency vibrational spectrum of $\mathrm{CO}$ and ethylene coadsorbed on a

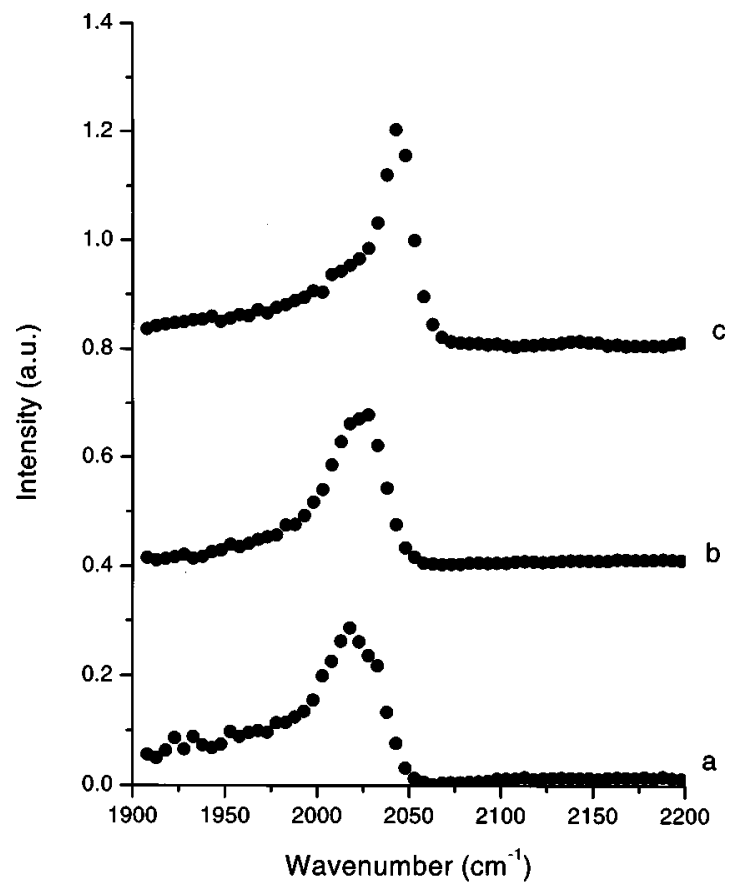

(a)

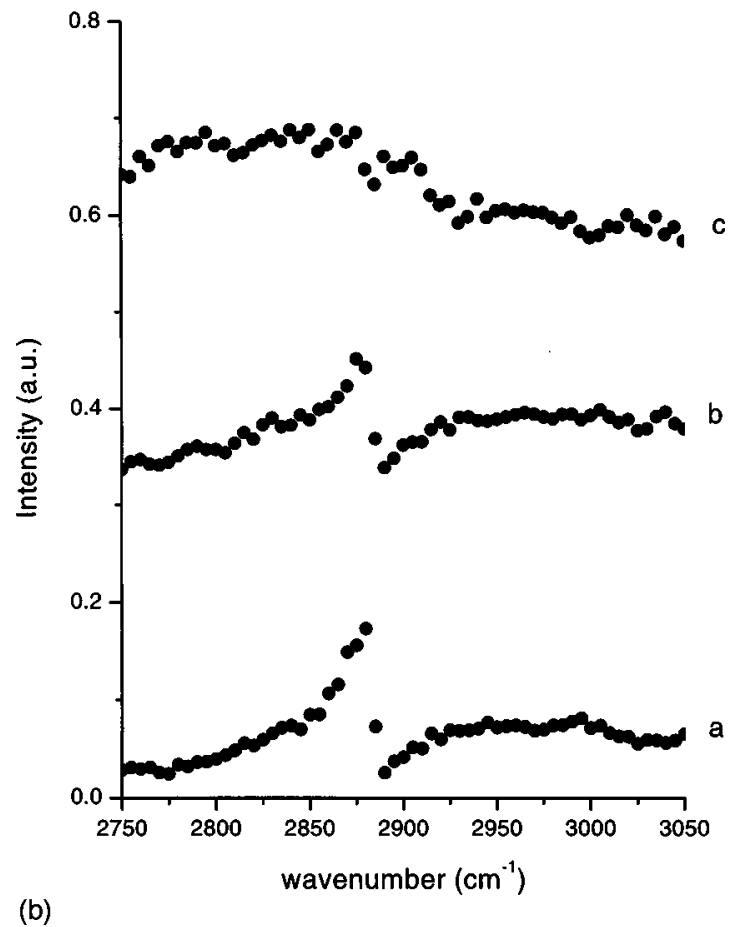

FIG. 4. (a) The SFG spectra of CO adsorbed on Pt(111) surface that has been predosed with $10 \mathrm{~L}$ of ethylene at $\mathrm{CO}$ pressure of (a) $10 \mathrm{~L}$ of $\mathrm{CO}$, (b) $10^{-7}$ Torr of CO, (c) 400 Torr of CO. (b) The SFG spectra of ethylidyne produced by $10 \mathrm{~L}$ exposure of ethylene on $\mathrm{Pt}(111)$ surface at various $\mathrm{CO}$ pressures: (a) $10 \mathrm{~L}$ of CO, (b) $10^{-7}$ Torr of CO, (c) 400 Torr of CO.

Pt(111) crystal [Figs. 4(a) and 4(b)]. Separate studies of CO and ethylene on $\mathrm{Pt}(111)$ have been done extensively by traditional surface science techniques and SFG. ${ }^{2,3,5,6}$ However, coadsorption studies have been largely limited to UHV and linear spectroscopy.

A Pt(111) crystal was cleaned by cycles of 12 min argon sputtering $\left(3 \times 10^{-5}\right.$ Torr Ar pressure, $1000 \mathrm{~V}$, and $20 \mathrm{~mA}$ emission current) and heating in oxygen $\left(5 \times 10^{-7}\right.$ Torr $\mathrm{O}_{2}$, 

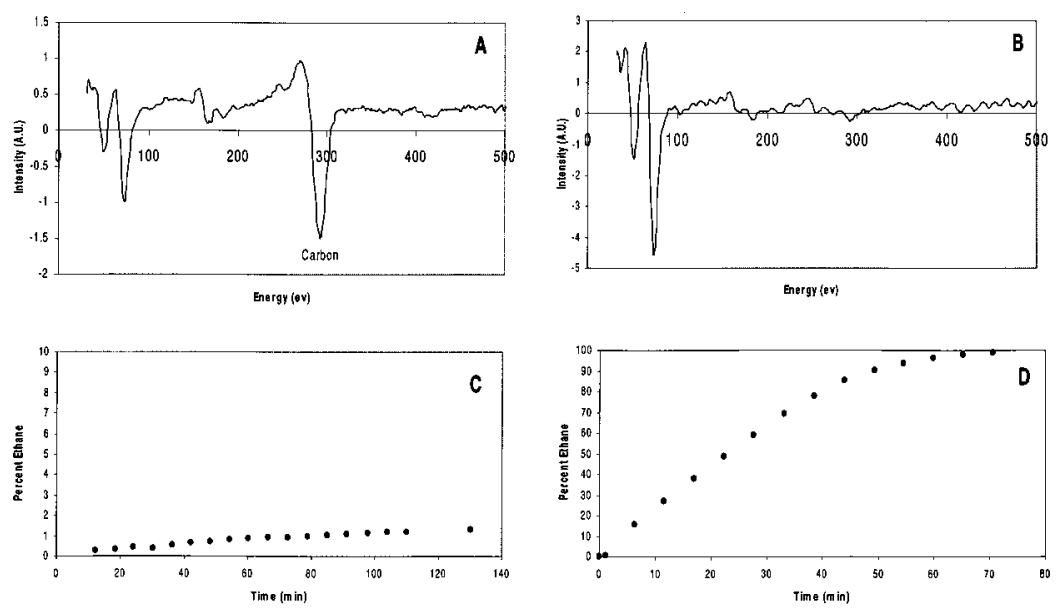

FIG. 5. (a) Auger spectrum of the carbon-covered $\mathrm{Pt}(111)$ crystal, (b) Auger spectrum of the clean $\mathrm{Pt}(111)$ crystal, (c) ethane accumulation as a result of ethylene hydrogenation on the carbon covered $\mathrm{Pt}(111)$ crystal surface, and (d) ethane accumulation as a result of ethylene hydrogenation on the clean $\mathrm{Pt}(111)$ crystal surface.
$1123 \mathrm{~K})$ in the UHV chamber. As the last step of cleaning following the oxygen treatment, the sample was annealed for 2 min at $2 \times 10^{-9}$ Torr and $1133 \mathrm{~K}$ to form a clean and well-ordered surface. Auger electron spectroscopy was used to check the surface cleanness. Following the annealing step and cooling to room temperature, the sample was exposed to $10 \mathrm{~L}$ of ethylene and then $10 \mathrm{~L}$ of $\mathrm{CO}$ at 400 and $300 \mathrm{~K}$, respectively. In Figs. 4(a) and 4(b), the simultaneous SFG spectrum of $\mathrm{CO}$ and ethylene at room temperature are shown. The CO peak appears shifted to 2020 from 2095 $\mathrm{cm}^{-1}$ for $\mathrm{CO}$ absorbed on $\mathrm{Pt}(111)$ at the atop sites. The ethylene adsorbs as ethylidyne on the surface with its vibrational peak at $2880 \mathrm{~cm}^{-1}$. No frequency shift in the ethylidyne peak was observed on coadsorption. When $\mathrm{CO}$ pressure in the cell was kept at $1 \times 10^{-7}$ Torr, the $\mathrm{CO}$ peak intensity increased while the intensity of ethylidyne peak decreased. At 400 Torr of CO, the CO peak position shifted to 2040 $\mathrm{cm}^{-1}$, however, no clear resonant feature was observed in the $\mathrm{CH}$ stretching region. This result indicates that the presence of high pressure $\mathrm{CO}$ displaces the ethylidyne from the $\operatorname{Pt}(111)$ surface.

To demonstrate the utility of the high-pressure cell for probing reaction kinetics, ethylene hydrogenation on $\mathrm{Pt}(111)$ was carried out. In Fig. 5, the plots of percentage of ethane accumulation versus time from a carbon covered and a cleaned $\operatorname{Pt}(111)$ crystal are shown. The corresponding Auger spectra show the relative coverages of carbon on the surfaces. The carbon covered $\mathrm{Pt}(111)$ surface was prepared by cracking $10 \mathrm{~L}$ of ethylene in UHV. On the carbon covered surface, less than $1.5 \%$ ethane was produced after running the reaction for over $2 \mathrm{~h}$ at $298 \mathrm{~K}$ with 10 Torr ethylene, 120 Torr hydrogen, and 630 Torr of helium as makeup gas to 1 atm. Without the sample, the reaction cell alone showed no reaction after 1 with 20 Torr ethylene, 40 Torr hydrogen, and 700 Torr $\mathrm{He}$ at room temperature. The cleaned $\mathrm{Pt}(111)$ surface shows the expected reactivity. ${ }^{3}$ At 10 Torr ethylene, 100
Torr hydrogen, and 650 Torr helium at room temperature, the ethylene was completely hydrogenated after $70 \mathrm{~min}$.

Through the combination of a UHVHP reaction system and a two OPA/OPG laser system, we are now able to measure simultaneously the SFG vibrational spectra of two different surface species in an environment ranging from UHV to high pressures. Together with reaction data collected by gas chromatography, this will allow detailed studies of the role of catalytic promoters and inhibitors and possible existence of reaction intermediate species.

\section{ACKNOWLEDGMENTS}

This work was supported by the Director, Office of Energy Research, Office of Basic Energy Sciences, and Materials Science Division, of the US Department of Energy. The authors would also like to thank J. Wu for fabricating numerous alloys used in the construction of the cell.

${ }^{1}$ Y. R. Shen, Nature (London) 337, 519 (1989).

${ }^{2}$ X. Su, P. C. Cremer, Y. R. Shen, and G. A. Somorjai, Phys. Rev. Lett. 77, 3858 (1996)

${ }^{3}$ P. C. Cremer, X. Su, Y. R. Shen, and G. A. Somorjai, J. Phys. Chem. 100, 16302 (1996).

${ }^{4}$ A. Bandara, S. Dobashi, J. Kubota, K. Onda, A. Wada, K. Domen, C. Hirose, and S. S. Kano, Surf. Sci. 387, 312 (1997).

${ }^{5}$ C. Klunker, M. Balden, S. Lehwald, and W. Daum, Surf. Sci. 360, 104 (1996)

${ }^{6}$ H. Harle, K. Mendel, U. Metka, H. R. Volpp, L. Willms, and J. Wolfrum, Chem. Phys. Lett. 279, 275 (1997).

${ }^{7}$ T. G. Rucker, K. Franck, D. Colimb, M. A. Logan, and G. A. Somorjai, Rev. Sci. Instrum. 58, 2292 (1987).

${ }^{8}$ A. Ludviksson, J. Yoshihara, and C. T. Campbell, Rev. Sci. Instrum. 66, 4370 (1995).

${ }^{9}$ J. Szanyi and D. W. Goodman, Rev. Sci. Instrum. 64, 2350 (1993).

${ }^{10}$ Y. N. Wang, R. McAllister, R. G. Sherman, G. W. Simmons, and K. Klier, Rev. Sci. Instrum. 63, 5767 (1992).

${ }^{11}$ R. A. Campbell and D. W. Goodman, Rev. Sci. Instrum. 63, 172 (1992).

${ }^{12}$ T. A. Jachimowski and J. Lauterbach, Rev. Sci. Instrum. 69, 2757 (1998).

${ }^{13}$ J. Y. Zhang, J. Y. Huang, and Y. R. Shen, Optical Parametric Generation and Amplification, 1st ed. (Harwood, Luxembourg, 1995), Vol. 19. 